Интернет-журнал «Мир науки» ISSN 2309-4265 http://mir-nauki.com/

2016, Том 4, номер 2 (март - апрель) http://mir-nauki.com/vol4-2.html

URL статьи: http://mir-nauki.com/PDF/15PDMN216.pdf

Статья опубликована 15.04.2016

Ссылка для цитирования этой статьи:

Бояров Е.Н. Организационно-педагогические условия подготовки бакалавров образования в области безопасности жизнедеятельности в безопасной информационной образовательной среде // Интернет-журнал «Мир науки» 2016, Том 4, номер 2 http://mir-nauki.com/PDF/15PDMN216.pdf (доступ свободный). Загл. с экрана. Яз. рус., англ.

УДК 37.022

Бояров Евгений Николаевич

ФГБОУ ВО «Сахалинский государственный университет», Россия, Южно-Сахалинск Доцент кафедры «Безопасности жизнедеятельности»

Кандидат педагогических наук

E-mail: e.boyarov@mail.ru

\title{
Организационно-педагогические условия подготовки бакалавров образования в области безопасности жизнедеятельности в безопасной информационной образовательной среде
}

Аннотация. Статья посвящена выявлению организационно-педагогических условий подготовки бакалавров образования в области безопасности жизнедеятельности, позволяющих эффективно формировать профессиональную и безопасную информационносредовую компетентность у будущего педагога в безопасной информационной образовательной среде. Автором проведен анализ существующих определений понятия «условия», применяемых в педагогических исследованиях.

В современном высшем педагогическом образовательном пространстве проблема формирования конкурентоспособной личности бакалавра образования в области безопасности жизнедеятельности, способного не только противостоять всем вызовам и угрозам личности, общества и государства, но быть готовым к ведению педагогической и культурнопросветительской деятельности, становится генеральной линией системы образования.

Несмотря на то, что в современной науке категория «условия» применительно к организации педагогического исследования представлена достаточно широко, авторское видение организационно-педагогических условий как неотъемлемого элемента подготовки бакалавра образования раскрыто применительно к безопасной информационной образовательной среде.

На основе проведенного анализа автором предложены основные группы условий (нормативно-правовые, мотивационные, организационно-методические, кадровые, материально-технические, результативно-оценочные), способствующих формированию безопасной информационно-средовой компетентности будущих бакалавров образования в области безопасности жизнедеятельности на основе системно-структурного, информационного и средового подходов с учетом ведущей роли адаптивного подхода как метаподхода.

Ключевые слова: подготовка бакалавров образования; безопасность жизнедеятельности; экспериментальное исследование; педагогические условия; нормативно- 
правовые условия; мотивационные условия; организационно-методические условия; кадровые условия; материально-технические условия; результативно-оценочные условия

Проблема организации и планирования педагогического эксперимента выступает в теории и практике педагогики высшей школы как одна из основных общетеоретических проблем, решение которой ведется в трудах многих известных педагогов С.И. Архангельского, В.И. Михеева, Ю.К. Бабанского, В.И. Журавлева, В.И. Загвязинского, А.И. Пискунова и других.

Организация педагогического эксперимента связана с планированием его проведения, которое определяет последовательность всех этапов работы, а также с подготовкой всех условий, обеспечивающих полноценное исследование.

При организации экспериментального исследования мы основывались на опыте, накопленном к настоящему времени в педагогической науке и практике подготовки студентов по направлению подготовки «Педагогическое образование», профиль «Образование в области безопасности жизнедеятельности (В.П. Соломин, П.В. Станкевич, С.В. Абрамова и других) [1, 10, 11 и др.].

В ходе поискового эксперимента (2008-2015 гг.) нами были разработаны организационно-педагогические условия для предметно-методической подготовки бакалавров образования в области безопасности жизнедеятельности в целях достижения результатов обучения студентов - формирование профессиональной компетентности в целом и безопасной информационно-средовой компетентности в частности [5].

Анализ философской и психолого-педагогической литературы показал, что понятие «условие» трактуется как «категория, выражающая отношение предмета к окружающим явлениям, без которых он существовать не может: сам предмет при этом рассматривается как нечто обусловленное, а условие как относительно внешнее по отношению к предмету многообразия объективного мира, то есть, условие - это то, от чего зависит предмет, комплекс предметов, характер их взаимодействия, из наличия которого следует возможность существования, функционирования и развития данного предмета» [13].

В рамках образовательного процесса в исследованиях Е.Ф. Бехтеновой педагогические условия определяются как качественная характеристика основных факторов, процессов и явлений образовательной среды, отражающая основные требования к организации деятельности» [4].

Определяя педагогические условия В.Н. Кокорев делает акцент на совокупность объективных возможностей, обстоятельств педагогического процесса, целенаправленно создаваемых и реализуемых в образовательной среде и обеспечивающих решение поставленных педагогических задач [8].

В широком смысле А.Я. Найн определяет педагогические условия как совокупность конечных результатов действия социально-педагогических процессов на данном этапе развития общества [9].

Учитывая особенности системы высшего педагогического образования В.А. Фатеев полагает целесообразным заявить о психолого-педагогических условиях, под которыми он понимает конкретные способы педагогического взаимодействия, взаимосвязанных мер в учебно-воспитательном процессе, направленных на формирование субъектных свойств личности, учитывая психологические особенности, продуктивные и эффективные способы и приемы деятельности в заданных условиях [12]. 
Опираясь на вышеназванные определения, в контексте предмета и задач проводимого исследования определим организационно-педагогические условия подготовки бакалавров образования в области безопасности жизнедеятельности как целенаправленно организованную преподавателем безопасную информационную образовательную среду с совокупностью объективных возможностей содержания, форм, методов, средств, педагогических приемов и технологий, направленных на решение задач формирования профессиональной компетентности.

На основании системного анализа, анализа литературных источников, нормативноправовых документов и собственного опыта, в рамках проведенного исследования, приведем основные группы условий, способствующих формированию безопасной информационносредовой компетентности будущих бакалавров образования в области безопасности жизнедеятельности на основе системно-структурного, информационного и средового подходов с учетом ведущей роли адаптивного подхода как метаподхода.

1. Нормативно-правовые условия, которые предполагают разработку программных документов, обеспечивающих:

- подготовку нормативно-правовой базы для разработки и использования безопасной информационной образовательной среды (положения, регламенты, приказы, соглашения с работодателями, логины, пароли, права доступа и других), механизмов их экспертизы и сертификации при необходимости;

- $\quad$ права студентов на доступные, актуальные, объективные, адекватные информационные образовательные ресурсы в безопасной информационной образовательной среде;

- $\quad$ доступ образовательного учреждения к распределенным базам и банкам данных ведущих мировых и российских информационных репозитариев на основе заключенных договоров и соглашений;

- $\quad$ взаимодействие образовательных учреждений на недискриминационной основе (двусторонний информационно-методический обмен);

- эффективное управление образовательным учреждением с использованием информационно-коммуникационных технологий;

- обязательность участия обучающихся, заинтересованной, реальных и потенциальных работодателей в разработке ООП, проектировании безопасной информационной образовательной среды образовательного учреждения, формировании и реализации индивидуальных образовательных маршрутов.

Рассматриваемая группа условий способствует созданию и развитию новых форм сетевого сотрудничества различных образовательных учреждений, в том числе в системе «школа - вуз», позволяющих успешно преодолеть несовершенство реализации инноваций в образовательную практику, что в целом будет способствовать перестройке деятельности образовательных учреждений, которые ищут новые формы сетевого взаимодействия, механизмы организации системного партнерства и взаимовыгодного сотрудничества, направленные на достижение социального и экономического благосостояния, конкурентоспособности на рынке труда [6].

Кроме того, при современном уровне развития интерактивных сервисов общения в Интернете (чат, ICQ, Skype, гостевые книги, форумы, блоги, wiki, online видеолекции и консультации и т.д.), живое общение в сети становиться все более эффективным, особенно, если посредством безопасной информационной образовательной среды комбинировать эти 
инструменты общения, оптимизировать средства доставки информации за счет увеличения скоростных каналов связи и обработки получаемой в процессе взаимодействия учебной информации. При этом нормативно-правовые условия направлены на ликвидацию «цифрового неравенства», связанного с отсутствием нормативно-правовой документации необходимой всем категориям пользователей в безопасной информационной образовательной среде.

2. Мотивационные условия, которые включают в себя создание атмосферы позитивного отношения к безопасной информационно-средовой деятельности путем стимулирования ее активных участников посредством системы рейтингового контроля, популяризации научных достижений среди студентов и преподавателей, усиления влияния науки на решение учебных и воспитательных задач в процессе профессиональной подготовки бакалавров в безопасной информационной образовательной среде. Кроме того, данные условия предполагают необходимость мотивации для обоснованного выбора студентами своего индивидуального образовательного маршрута в соответствии с их интересами и способностями. [7]:

При этом мотивационная основа учебной деятельности включает несколько элементов

- $\quad$ сосредоточение внимания на учебной ситуации, необходимое для включения студентов в учебную деятельность, для выполнения разнообразных учебных задания, поскольку внимание, то есть способность сосредоточиться на усвоении заданных объектов, то необходимое условие всех познавательных процессов. Внимание, таким образом, является начальной фазой учебной деятельности студента;

- осознание смысла предстоящей работы, которое помогает обучающемуся сориентироваться в деятельности и позволяет ему получить информацию о предмете потребности, активизирующую учебную деятельность. При этом получение студентом образовательной информации и осознании ими личностного смысла предстоящей образовательной деятельности, в свою очередь выражается в готовности действовать;

- осознание выбора мотива, которое заключается в осознании актуальной потребности и выборе мотива получения высшего образования. Внешние побуждения актуализируют необходимую образовательную потребность студента, она стимулирует личность на совершение определенных действий, но решение действовать принимает сам студент. Под влиянием педагогических воздействий студент осознает свои потребности и действует, побуждаемый значимым в данной ситуации мотивом, выбирая необходимые ему мотивы учебной деятельности (осознает необходимость овладения новыми знаниями и умениями, стремится преодолеть познавательное затруднение, выработать в себе необходимые способности и качества);

- целеполагание, заключающееся в выработке у студента целей учебной деятельности. При этом постановка самим студентом цели, представляемой им в форме образа, осознаваемого, предвидимого результата безопасной информационно-средовой деятельности, актуализирует готовность к ее достижению и тем самым определяет дальнейшую направленность его действий;

- осуществление учебных действий, направленных на удовлетворение своих индивидуальных образовательных потребностей, - участвует в решении учебных задач или выполняет задание. При этом побуждения студента направлены на деятельность, соответствующую его индивидуальных способностям, возможностям и интересам; 
- сознание уверенности в правильности своих действий, заключающееся в стремление к достижению успеха. При этом мотивированность достижением проявляется в готовности стремиться к целям обучения и быть настойчивым в этом.

3. Организационно-методические условия, способствующие формированию предметных знаний, умений, навыков и компетенций студентов вуза, включают в себя:

- $\quad$ индивидуальность обучения - осуществление педагогического сотрудничества с каждым студентом, предоставление возможности обучения навыкам самостоятельной деятельности в проблемных ситуациях;

- $\quad$ гибкость обучения - предоставление широкого выбора форм и методов самостоятельного работы и самообразования;

- $\quad$ внутреннюю открытость - предоставление возможности самостоятельно планировать свои учебную деятельность, регулировать затраты времени;

- $\quad$ адаптивность - возможность, позволяющая студенту выбирать вариативную часть учебного содержания в соответствии с профилем специальности, а также отбирать необходимый объем материала, его источники, интерпретаторов, в результате он является главным и основным субъектом образовательной деятельности;

- $\quad$ контекстные технологии - включение студентов в моменты проведения экспериментов, проводимых на лекциях и практических занятиях. Контекстнопрофессиональные занятия способствуют развитию готовности к решению ситуационных задач в сфере будущей профессиональной деятельности студентов. Для того чтобы вывести студента на этапе профессиональной подготовки на новый уровень понимания особенностей и трудностей в профессии и способствовать развитию рефлексии, необходимо включать в материал лекции или практического занятия ситуативные задания регионального характера. Достоинством проведения подобных занятий является формирование коллективного понимания не только специфики, но и сложностей будущей профессии.

Учебно-методическое обеспечение составляют методы и методические приемы, формы и средства обучения, обуславливающие решение практических задач подготовки бакалавров образования в области безопасности жизнедеятельности.

В безопасной информационной образовательной среде комплексное использование словесных, наглядных и практических методов с применением мультимедийных средств обучения и наглядности в процессе подготовки бакалавров образования в области безопасности жизнедеятельности позволяло проиллюстрировать обобщенные и абстрактные новые предметные знания по безопасности жизнедеятельности.

Данные условия предполагают усиление предметно-методического (деятельностного) аспекта содержания безопасной информационно-средовой деятельности студентов в процессе их предметно-методической подготовки. Это возможно осуществить посредством:

- $\quad$ разработки и реализации специальных учебно-педагогических ситуаций в процессе предметно-методического обучения;

- использования разноуровневых исследовательских, проектных задач для организации индивидуальной и групповой работы студентов;

- $\quad$ включения в предметно-методическую подготовку современных личностноориентированных образовательных технологий на основе средового подхода, направленных на проектирования его индивидуального образовательного маршрута (проблемное обучение, технология сотрудничества и др.); 
- обсуждения и планирования совместной деятельности с внешними специалистами (учителями-предметниками, руководителем образовательного учреждения, экскурсоводом, педагогом дополнительного образования и т.д.);

- создания соответствующей системы организации учебной и педагогической практики, позволяющей устранить противоречие между достижениями в педагогической науке и их реализацией в образовательной практике (экспериментальные площадки, педагогическая интернатура и др.);

- $\quad$ реализации рефлексии и корректировки процесса предметно-методической подготовки студентов в экспериментальных условиях.

Еще одним организационно-методическим условием являются информационные условия, которые связаны с обеспечением образовательной деятельности студентов соответствующей информацией (безопасными информационными образовательными ресурсами - контентом: научной, научно-популярной, методической и периодической литературой, банками и базами данных и знаний, педагогическими программными средствами, единым порталом информационных образовательных ресурсов и др.). В целом, безопасные информационные образовательные ресурсы рассматриваются нами как совокупность информации методического характера, используемой в процессе обучения студентов, и представлены учебно-методическими комплектами (печатные и электронные) для обучения основам безопасности жизнедеятельности в школе, научно-методической литературой, банком ситуационных заданий, специализированными интернет-сайтами, форумами, блогами и т.д., обладающими свойствами информации, устойчивыми к внешним и внутренним негативным воздействиям, и не оказывающие такого воздействия на обучающихся.

Данная группа условий обеспечивает научно-информационный сетевой обмен между студентами различных вузов, а также многообразие форм участия студентов в научнопрактических мероприятиях различного уровня и позволяет осуществлять сотрудничество вуза со школами (педагогический консалтинг и др.), способствующее вовлечению студентов в процесс создания, функционирования, модерирования безопасной информационной образовательной среды образовательных учреждений.

4. Кадровые условия, которые связаны с отбором педагогических кадров для успешного осуществления педагогического сопровождения предметно-методической подготовки бакалавров образования в области безопасности жизнедеятельности; повышением их квалификации; привлечением высококвалифицированного профессорскопреподавательского состава, а также учителей, руководителей образовательных учреждений к совместному построению безопасной информационной образовательной среды образовательного учреждения, призванным решать конкретные проблемы, существующие в межсетевом образовательном пространстве.

Требования к кадровым условиям реализации основной образовательной программы высшего педагогического образования включают:

- укомплектованность образовательного учреждения педагогическими, руководящими и иными работниками;

- у уровень квалификации педагогических и иных работников образовательного учреждения;

- $\quad$ непрерывность профессионального развития педагогических работников образовательного учреждения. 
Кадровые условия являются основой для разработки должностных инструкций, содержащих конкретный перечень должностных обязанностей работников, с учетом особенностей организации труда и управления, а также прав, ответственности и компетентности работников образовательной организации служат квалификационные характеристики, представленные в Едином квалификационном справочнике должностей руководителей, специалистов и служащих (раздел «Квалификационные характеристики должностей работников образования»).

Для эффективного использования возможностей безопасной информационной образовательной среды преподаватель должен соответствовать следующим минимальным требованиям:

- владеть основами работы на компьютере, в том числе уметь использовать информационно-образовательную среду;

- владеть мультимедийными информационными ресурсами, их программным обеспечением;

- $\quad$ использовать современные информационно-коммуникационные технологии для сбора, обработки и анализ информации;

- использовать в образовательном процессе разнообразные ресурсы (образовательные, информационные и др.), в том числе потенциал других учебных предметов;

- $\quad$ планировать организацию учебного процесса с использованием возможностей образовательной среды, в том числе информационной;

- $\quad$ навыками работы с программными средствами общего и профессионального значения;

- способами ориентации в профессиональных источниках информации (журналы, сайты, образовательные порталы и т.д.);

- $\quad$ способами совершенствования профессиональных знаний и умений путем использования возможностей информационной среды образовательного учреждения, региона, области, страны и др.

5. Материально-технические условия, которые включают создание необходимой учебно-материальной базы (объекты электронной вычислительной техники, средства мультимедиа, средств массовой информации и коммуникации, другие средства обучения) для проектирования и реализации предметно-методической подготовки бакалавров образования в области безопасности жизнедеятельности в безопасной информационной образовательной среде и определяют наличие:

- у учебно-методической базы (базовые школы, учреждения дополнительного образования, научные, социально-культурные и производственные организации, специализированные «экспериментальные площадки» (Областной художественный музей дополненной реальности, ведомственные вычислительные центры, интернет-клубы и др.)) для проведения тематических экскурсий, учебной и педагогической практики;

- $\quad$ оборудованных учебных стендов для проведения лабораторных и практических занятий со студентами в пространстве безопасной информационной образовательной среды образовательного учреждения;

- информационно-телекоммуникационная инфраструктура образовательного учреждения, позволяющая участвовать в межвузовском сетевом информационном обмене; 
- учебные кабинеты с автоматизированными рабочими местами, имеющими возможность подключения к локальным (вузовским), межвузовским (сетевым) и глобальным (распределенным российским и зарубежным) безопасным информационным образовательным ресурсам;

- $\quad$ модельный школьный кабинет основ безопасности жизнедеятельности в высшем учебном заведении.

6. Результативно-оценочные условия, включающие разнообразные виды диагностики процесса и результатов обучения студентов: различные методы контроля предметных знаний и умений студентов: тестирование, индивидуальный устный опрос, письменные работы, беседа, выполнение практических работ, написание и защита рефератов и докладов, решение ситуационных задач и задач на моделирование и прогнозирование, зачет, экзамен, курсовая работа и др.

При этом комплексная оценка уровня сформированности компетенций студентов проводятся в вузах в форме аттестации, на базе балльно-рейтинговой системы, организации элементов безопасной информационной образовательной среды и проектирования, позволяющих выявлять и диагностировать личностный потенциал, интеллектуальные, профессиональные и творческие способности студентов, методом адаптивной и мультипликативной свертки, а также экспертного оценивания и самооценки на соответствие предъявляемым требованиям.

В Сахалинском государственном университете балльно-рейтинговая система оценки знаний студента осуществляется на основе разработанного в соответствии с п. 7.1. ГОСТ Р ИСО 9001«Системы менеджмента качества. Требования» стандарта организации, СТО «Балльно-рейтинговая система оценки знаний студентов СахГУ-011-2012».

Балльно-рейтинговая система основывается на интегральной оценке результатов всех видов учебной деятельности студента за весь период обучения и учитывает результаты изучения всех дисциплин и/или модулей рабочего учебного плана; прохождения всех видов практик; государственной итоговой аттестации; выполнения и защиты курсовой и выпускной квалификационной работ.

Каждая дисциплина и/или модуль рабочего учебного плана оценивается по 100балльной шкале. Перевод баллов в оценки пятибалльной системы осуществляется следующим образом: 85 - 100 баллов - «отлично»; 70 - 84 балла - «хорошо»; 52 - 69 баллов «удовлетворительно»; 0 - 51 балл - «неудовлетворительно».

Больший вклад оценок за текущую работу в общую оценку студента по освоению содержания дисциплины и/или модуля определяет важность четкой организации и объективности текущего контроля уровня усвоения знаний, умений и готовности осуществлять профессиональную деятельность. Вклад текущей работы студентов в итоговую оценку по каждой учебной дисциплине и/или модулю должен составлять не менее 50\% (50 баллов из 100 возможных) и складывается из:

- посещения лекционных и практических занятий;

• выполнения индивидуального задания;

- работы на практических (семинарских) занятиях;

- $\quad$ самостоятельной работы студентов (выполнение домашних заданий, написание рефератов, выполнение индивидуальных работ, не предусмотренных учебным планом и т.д.). 
Экспертная оценка профессиональной деятельности бакалавра образования в области безопасности жизнедеятельности позволяет определить уровень его квалификации на основе анализа сформированности профессиональной компетентности.

При проведении экспертной оценки профессиональной деятельности бакалавра образования в области безопасности жизнедеятельности, прежде всего, важно ответить на вопросы о том, по каким параметрам осуществляется оценка каждой из выделенных компетенций. С этой целью нами применялся метод групповых экспертных оценок [1].

Экспертам предлагалось оценить профессиональные компетенции бакалавра образования в области безопасности жизнедеятельности, которые отражают отдельные профессиональные качества, необходимые для профессиональной деятельности, используя общепринятую 5-ти балльную шкалу, которая имела следующие уровни:

«5»- очень высокая степень выраженности указанной в утверждении характеристики. Она проявляется в подавляющем большинстве ситуаций, является устойчивой, полностью соответствует типичным качествам и поведению бакалавров образования в области безопасности жизнедеятельности. Ответ экспертов - «да».

«4»- высокая степень выраженности характеристики. Она часто проявляется при решении конкретных ситуационных задач. Иногда возникают случаи, когда качества или поведение испытуемого не соответствуют утверждению. Ответ экспертов - «скорее да, чем нет».

«3»- средняя степень выраженности характеристики. В некоторых ситуациях качества и поведение специалистов образования в области безопасности жизнедеятельности соответствуют утверждению, в некоторых - не соответствуют. Ответ экспертов - «среднее значение».

«2»-слабая степень выраженности характеристики. Она редко проявляется в конкретных ситуациях. Поведение и качества бакалавров образования в области безопасности жизнедеятельности лишь иногда соответствуют утверждению. Ответ экспертов - «скорее нет, чем да».

«1»-характеристика не представлена в деятельности испытуемого. Качества и поведение бакалавров образования в области безопасности жизнедеятельности не соответствуют содержанию утверждения. Ответ экспертов - «нет».

Таким образом, выявление организационно-педагогических условий подготовки бакалавров образования в области безопасности жизнедеятельности в безопасной информационной образовательной сред, обеспечивающих функционирование и развитие педагогической системы, целостного педагогического процесса является одной из важных задач педагогических исследований, успешное решение которой, как правило, составляет научную новизну исследования и обусловливает его практическую ценность. 


\section{ЛИТЕРАТУРА}

1. Абрамова, С.В. Теория и практика подготовки бакалавров образования в области безопасности жизнедеятельности: монография / С.В. Абрамова - СанктПетербург: изд-во РГПУ им. А.И. Герцена, 2014. - 200 с.

2. Абрамова, С.В., Бояров, Е.Н. Реализация системного подхода в построении методической системы подготовки специалистов в образовательной области безопасности жизнедеятельности // В мире научных открытий. 2011. №4.1. С. 397-404.

3. Бабанский, Ю.К. Проблемы повышения эффективности педагогических исследований: Дидактический аспект. - М.: Педагогика, 1982. - 190 с.

4. Бехтенова, Е.Ф. Условия формирования проектной деятельности учащихся: дис. ... канд. пед. наук / Е.Ф. Бехтенова. - Новосибирск, 2006. - 320 с.

5. Бояров, Е.Н. Теоретические основы построения безопасной информационной образовательной среды подготовки педагогов в области безопасности жизнедеятельности // Социосфера. - 2012. - №4. - С. 101-106.

6. Верещагина, Н.О. Опыт и проблемы разработки и реализации магистерских образовательных программ в сетевой форме // Universum: Вестник Герценовского университета. - 2014. - №3-4. - С. 49.

7. Гребенюк, О.С., Гребенюк, Т.Б. Основы педагогики индивидуальности: Учеб. пособие / Калинингр. гос. ун-т. - Калининград, 2000. - 572 с.

8. Кокорев, В.Н. Педагогические условия реализации конвенции ООН с правах ребенка в современной школе: автореф. дис. ... канд. пед. наук / В.Н. Кокорев. Омск, 2007. - 19 с., с. 11.

9. Найн, А.Я. Педагогические инновации и научный эксперимент / А.Я. Найн // Педагогика. - 1989. - №2. - С. 12-19.

10. Соломин, В.П. Теоретико-методологические основы и особенности организации образовательного процесса в Институте естествознания педагогического университета: Монография. - СПб.: Издательство РГПУ им. А.И. Герцена, 1999. $-224 \mathrm{c}$.

11. Станкевич, П.В. Теория и практика подготовки бакалавра в системе многоуровневого естественнонаучного образования: / П.В. Станкевич // монография. СПб.: Изд-во «ТЕССА», 2006. - 164 с.

12. Фатеев, В.А. Формирование готовности будущего учителя физической культуры к реализации личностно ориентированного подхода / В.А. Фатеев // Физическая культура: воспитание, образование, тренировка. - 2007. - №6. - С. 63-65.

13. Философский энциклопедический словарь / С.С. Аверинцев, Л.Ф. Ильичев и др. - 2-е изд. - М.: Сов. энцикл., 1989. - 815 с. 


\title{
The organizational and pedagogical conditions of Bachelor of Education in Life Safety in a secure informational educational environment
}

\begin{abstract}
The article is devoted to the identification of the organizational and pedagogical conditions to educate of Bachelor of Education in Life Safety. This will form a professional competence and a secure information and environmental competence of the future teacher in a secure informational educational environment. The author analyzes the existing definitions of "conditions" concepts used in educational research.

In today's higher pedagogical educational space of the problem of forming a competitive personality Bachelor of Education in Life Safety, able not only to withstand all challenges and threats to the individual, society and state, but also to take on in the near future, the functions of the organization and management of educational, cultural and educational activities it becomes the general line of the education system.

Despite the fact that modern science category "conditions" in relation to the organization of pedagogical research is presented widely enough, the author's vision of organizational and pedagogical conditions as an integral part of training Bachelor of Education disclosed in relation to the secure informational educational environment.

Based on the analysis the author offers the basic set of conditions (legal, motivational, organizational and methodical, personnel, efficiently and assessment), contributing to the formation of a secure information-environmental competence of the Bachelor of Education in Life Safety based on system-structural approach, information approach and environmental approach, taking into account the leading role of adaptive approach as a meta-approach.
\end{abstract}

Keywords: educate of bachelor of education; life safety; experimental research; pedagogical conditions; legal and regulatory conditions; motivational conditions; organizational and methodical conditions; personnel condition; material and technical conditions; effectively and assessment conditions 


\section{REFERENCES}

1. Abramova, S.V. Teoriya i praktika podgotovki bakalavrov obrazovaniya v oblasti bezopasnosti zhiznedeyatel'nosti: monografiya / S.V. Abramova - Sankt-Peterburg: izd-vo RGPU im. A.I. Gertsena, 2014. - 200 s.

2. Abramova, S.V., Boyarov, E.N. Realizatsiya sistemnogo podkhoda $\mathrm{v}$ postroenii metodicheskoy sistemy podgotovki spetsialistov $\mathrm{v}$ obrazovatel'noy oblasti bezopasnosti zhiznedeyatel'nosti // V mire nauchnykh otkrytiy. 2011. №4.1. S. 397404.

3. Babanskiy, Yu.K. Problemy povysheniya effektivnosti pedagogicheskikh issledovaniy: Didakticheskiy aspekt. - M.: Pedagogika, 1982. - 190 s.

4. Bekhtenova, E.F. Usloviya formirovaniya proektnoy deyatel'nosti uchashchikhsya: dis. ... kand. ped. nauk / E.F. Bekhtenova. - Novosibirsk, 2006. - 320 s.

5. Boyarov, E.N. Teoreticheskie osnovy postroeniya bezopasnoy informatsionnoy obrazovatel'noy sredy podgotovki pedagogov $\mathrm{V}$ oblasti bezopasnosti zhiznedeyatel'nosti // Sotsiosfera. - 2012. - №4. - S. 101-106.

6. Vereshchagina, N.O. Opyt i problemy razrabotki i realizatsii magisterskikh obrazovatel'nykh programm v setevoy forme // Universum: Vestnik Gertsenovskogo universiteta. - 2014. - №3-4. - S. 49.

7. Grebenyuk, O.S., Grebenyuk, T.B. Osnovy pedagogiki individual'nosti: Ucheb. posobie / Kaliningr. gos. un-t. - Kaliningrad, 2000. - 572 s.

8. Kokorev, V.N. Pedagogicheskie usloviya realizatsii konventsii OON s pravakh rebenka v sovremennoy shkole: avtoref. dis. ... kand. ped. nauk / V.N. Kokorev. Omsk, 2007. - 19 s., s. 11.

9. Nayn, A.Ya. Pedagogicheskie innovatsii i nauchnyy eksperiment / A.Ya. Nayn // Pedagogika. - 1989. - №2. - S. 12-19.

10. Solomin, V.P. Teoretiko-metodologicheskie osnovy i osobennosti organizatsii obrazovatel'nogo protsessa $\mathrm{v}$ Institute estestvoznaniya pedagogicheskogo universiteta: Monografiya. - SPb.: Izdatel'stvo RGPU im. A.I. Gertsena, 1999. - 224 s.

11. Stankevich, P.V. Teoriya i praktika podgotovki bakalavra $\mathrm{v}$ sisteme mnogourovnevogo estestvennonauchnogo obrazovaniya: / P.V. Stankevich // monografiya. SPb.: Izd-vo «TESSA», 2006. - $164 \mathrm{~s}$.

12. Fateev, V.A. Formirovanie gotovnosti budushchego uchitelya fizicheskoy kul'tury k realizatsii lichnostno orientirovannogo podkhoda / V.A. Fateev // Fizicheskaya kul'tura: vospitanie, obrazovanie, trenirovka. - 2007. - №6. - S. 63-65.

13. Filosofskiy entsiklopedicheskiy slovar' / S.S. Averintsev, L.F. Il'ichev i dr. - 2-e izd. M.: Sov. entsikl., 1989. - 815 s. 